\title{
Entanglement of Imaging and Imagining of Nanotechnology
}

\author{
Martin Ruivenkamp • Arie Rip
}

Received: 6 May 2011 /Accepted: 24 June 2011 /Published online: 15 July 2011

(C) The Author(s) 2011. This article is published with open access at Springerlink.com

\begin{abstract}
Images, ranging from visualizations of the nanoscale to future visions, abound within and beyond the world of nanotechnology. Rather than the contrast between imaging, i.e. creating images that are understood as offering a view on what is out there, and imagining, i.e. creating images offering impressions of how the nanoscale could look like and images presenting visions of worlds that might be realized, it is the entanglement between imaging and imagining which is the key to understanding what images do. Three main arenas of entanglement of imag(in)ing and the tensions involved are discussed: production practices and use of visualizations of the nanoscale; imag(in)ing the future and the present; and entanglements of nanoscience and art. In these three arenas one sees struggles about which images might stand for nanotechnology, but also some stabilization of the entanglement of imag(in)ing, for example in established rules in the practices of visualizing the nanoscale. Three images have become iconic, through
\end{abstract}

M. Ruivenkamp $(\square)$

Centre for Society and Genomics, Institute for Science, Innovation and Society, Faculty of Science,

Radboud University Nijmegen,

PO-Box 9010, 6500 GL Nijmegen, The Netherlands e-mail: ruivenkamp@society-genomics.nl

\section{A. Rip}

Department Science, Technology, and Policy Studies

(ST PS), Faculty of Management and Governance, University of Twente,

PO-Box 217, 7500 AE Enschede, The Netherlands the combination of their wide reception and further circulation. All three, the IBM logo, the Foresight Institute's Nanogear image, and the so-called Nanolouse, depict actual or imagined technoscientific objects and are thus seen as representing technoscientific achievements - while marking out territory.

Keywords Artist's impressions · Images · Imagining · Representation of nanotechnology - Visualization of the nanoscale

\section{Introduction}

Within and beyond the world of nanoscience, images abound. There are lots of colourful images of structures at the nanoscale, based on visualizations of digital data created by scanning probe microscopy or other imaging instruments (as are made available to colleague nanoscientists). There are also artist's impressions, ranging from impressions of entities at the nanoscale to envisioning nanoachievements to be realized in the near or long-term future, including science-fiction type images of nanobots. One can distinguish imaging, that is, creating images based on data and aiming at resemblance, from imagining, where imagination is mobilized to create a vision of the nanoworld. Actually, imaging and imagining are always entangled, already in so-called scientific visualizations where expectations about how the nanoscale could look like steer the choices involved in making images [19]. 
The main topic of our paper is to trace such entanglements. A subsequent question then is what such entangled images stand for, not only representing in the sense of resemblance, but also in terms of what images do when representing the nanoscale. A clear example are images which demonstrate of technoscientific achievements.

In practice, there is a continuum ranging from 'visualizations of the nanoscale' adapted from original instrument-based data to so-called 'artist's impressions' (which need not be produced by artists; the phrase is used to indicate some freedom in visualizing) of how the nanoscale could look like, or how audiences may expect that it looks. Visions have an explicit orientation towards the future. This occurs already within science, for example when images indicate possible functions of complex molecular structures.

To capture the continuum of imaging and imagining, we will write 'imag(in)ing'. 'We will start by analyzing occurrences of imag(in)ing and the tensions involved. While imag(in)ing has to do with representation, which is often focused on making something present through resemblance, we emphasize representation as 'standing for' and being able to 'act for', as in 'political representation' (cf. [3]). Standing for and being able to act for, is somewhat independent of what is being 'stood for'. Thus, this notion of representation is broader than the epistemological puzzles, and debates, about reality (out there and/or in contrast with fiction). In the final part of our paper, we will discuss struggles about what the 'right' representation is, in terms of images that become iconic, and in that sense stand for, and are allowed to speak for, nanotechnology.

\section{Imag(in)ing the Invisible Nanoscale}

The nanoscale, invisible to the naked eye, is visualized through the use of a variety of imaging instruments. At the outset, it is not clear what the right imaging tools would be, and this relates to the basic problem how one can know whether the visualizations obtained actually visualize the nanoscale 'correctly'? Harry Collins highlighted the problem of choice between instruments

\footnotetext{
${ }^{1}$ After we developed this 'typographic entanglement' we found it had been used before, e.g. by Preston et al. [17].
}

that would be adequate to the task of studying unknown phenomena - a problem which he introduced as an experimenter's regress because there is no independent check of the correctness of the choice [5]. For the production of visualizations there is the additional question about the ways to produce images/ pictures that lead to reliable representations of the invisible. Just as the experimenter's regress can (and will) be stopped in practice when expectations about the unknown phenomenon become shared, 'expectations about how the invisible phenomena should "look" like, can provisionally stop the visualization regress' ([19]: 5).

A subsequent imaging challenge is to reach audiences which are not familiar with the production processes of the images. There will be '(..) a diffuse message about the nanoscale which has to be presented as clearly - and convincingly - as possible' ([19]: 9) to intended audiences. Artist's impressions may do such a job better than data-based images.

In visualization practices expectations about what can be 'seen' at the nanoscale and how the nanoscale should be visualized are to some extent internalized as rules about how to do it. The data-based images are manipulated to highlight the information they should convey, which is an accepted practice in the domain of science, as long as the scientific content remains unchanged. Artist's impressions of how the nanoscale could look like are similar, in the sense that imaging and imagining are also entangled. In other words 'scientific correctness' is mixed with expectations about the best way to visualize the nanoscale. Visualizations of the nanoscale as well as artist's impressions are used in scientific journals to show research results. ${ }^{2}$

Such practices are not uncontested. The cover of Science (see Fig. 1) was criticized in Ottino [14] and defended by Dekker (see [15]). Still, it shows how artist's impressions which do not depict scientific results 'correctly', make it to the cover of scientific

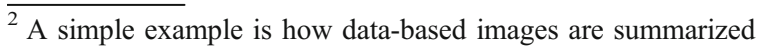
and effectively replaced by a drawing, which is equivalent to an artist's expression. Andre et al. [1] offer AFM images of a peptide in a cell wall (and check for possible artefacts). Towards the end they summarize their findings: "we provide several pieces of evidence which [...] argue for an architectural feature [...] (Fig. 7)". Their Fig. 7 is to visualize what the architecture really looks like, but labeled as a "schematic drawing" (also called a "cartoon") - the shift is not a problem for the authors, nor, presumably, for their readers.
} 


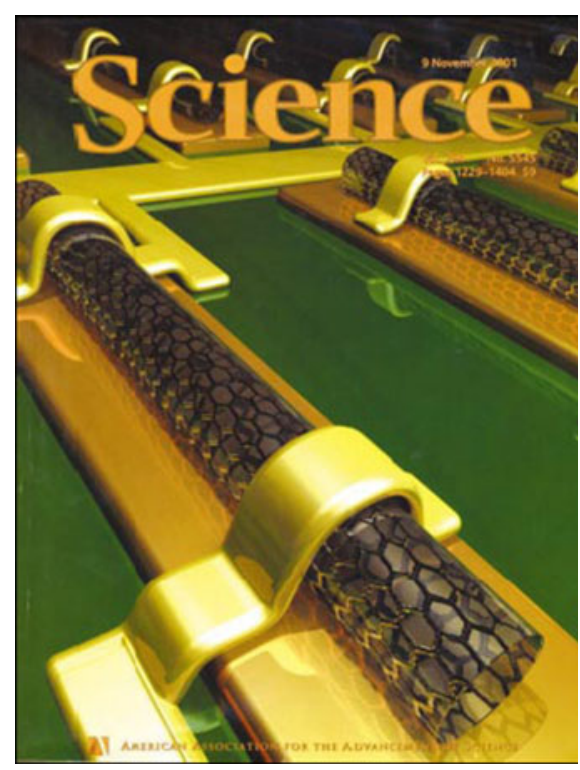

Fig. 1 Artist's impression of an array of nanotubes FETs overlaid with gold source and drain electrodes. This image was used for a cover of Science, and was subsequently criticized by Ottino, who argued that "if the carbon atoms are visible, then the much larger gold atoms in the structure should also be on view" ([14]:476). Dekker defended his approach as being a productive metaphor. Courtesy of: C. Dekker, TU Delft/Tremani

journals. ${ }^{3}$ When they do so, they come to stand for scientific achievements, and cover pictures are often presented on research groups' websites next to their list of publications.

\section{Practices of Entangling the Future and the Present}

As an emerging technology, nanotechnology comprises present achievements and visions of what it may become. While such combinations occur for all sorts of sciences and technologies (see Van Lente [24] on promising technologies) this appears particularly striking in nanotechnology. Imag(in)ing practices of entangling the future and the present are widespread in nanotechnology. Mody [12] argues that nanotechnology, in contrast to, for example,

\footnotetext{
${ }^{3}$ On the cover image, the carbon atoms of the depicted nanotubes are recognizable, but the much larger gold atoms are not detailed, are depicted as a bulk material. The article itself is Bachtold et al. [2]. Dekker's defense was reported in an interview with Dekker in a Dutch quality newspaper [15].
}

physics and chemistry, 'seems decidedly nonpresentist' and that 'nanotechnologists work as much in this future world as in the present' ([12]: 108). Then, there is the design orientation in nanotechnology, where a possible future is projected to be realized by a present design. With computer simulations playing an important role, much of nanotechnology's 'created reality' thus has a virtual, 'yet-to-be-realized quality' [10].

Kaiser [9] adds another twist:

'They [future visions] have been invented and are presented with the strong probability claim that they will become reality in the future. From a modal logical point of view, they don't represent possible worlds in the fictional universe; on the contrary, they constitute future worlds in ours' ([9]: 667).

If one wants to use categories like 'reality' and 'fiction' (as actors often do), one can say that boundaries between 'reality' and 'fiction' are blurred in the nanorealm, and this will be reflected in images of nanotechnology. Scientists produce images - equivalent to artist's impressions - that show what could be possible applications for nanotechnology. Images of bucky balls, molecular machines, new uses of carbon nanotubes, are created to make a possible future present. Artists offer their (own or commissioned) visions of nanotechnology's potential future applications.

As soon as the future is incorporated, there is no sharp boundary between images that articulate directions of further research and more open-ended visions of new performances which then merge with futuristic visions. Some actors will attempt to separate 'science' ('reality') from 'science fiction'. This can be a tactic to have their project prevail over that of others (this tactic has been deployed by critics of Drexler's visions of molecular manufacturing, cf. [18]). Or it can be a defensive move to avoid being called to account for possible negative implications of investing in nanotechnology research ('that's only fiction').

Arguments for disentangling the future from the present also occur in relation to lay-audiences. Such an argument would run like: it should be made clear which images are realistic and which are fictive, so as to avoid giving the false impression that (say) nanobots have already been built. 
Ottino [14] extended his crusade for correctness to the Nanolouse image (see Fig. 2):

'The image looks so real that it is easy to imagine a viewer being fooled into believing it has already been built. This is important in terms of public reaction, especially in the backdrop of scenarios such as in Michael Crichton's new novel Prey, which portrays swarms of self-replicating nanomachines destroying all other life forms that they encounter' ([14]: 476).

Ottino links his criticism with a concern about public acceptance of nanotechnology, if such images should come to stand for nanotechnology in the public eye. The public, however, may well be more discerning than he projects it to be. Still, the image does contain an ambivalence, which is brought out in how it has been presented on the BBC website (www. bbc.co.uk). On one occasion it was positioned as the 2002 winner of the Visions of Science award: 'The more over-hyped applications see tiny machines roaming the body to cure diseases'. On another occasion, realistic possibilities were emphasized: the Nanolouse image 'intends to show one of the possible applications of nanotechnology in medicine in the future - microscopic machines roaming the body, injecting or taking samples for tests'.

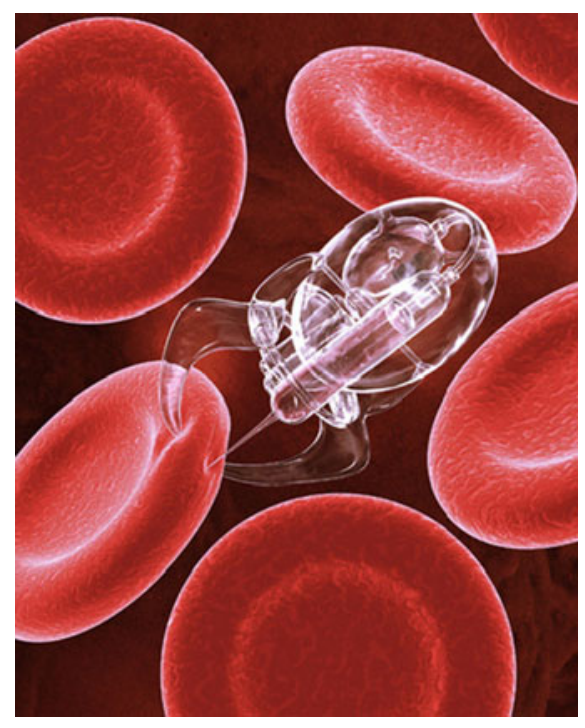

Fig. 2 The Nanolouse image; over-hyped or a possible application of nanotechnology in medicine in the future. Source: Ottino [14]
Continuing with this example, it is interesting that the Nanolouse image has been often used in the world of science. In the period 2005-2007, the image was used in presentations about drug delivery, nanoprobes and (N)MEMS, as an illustration and occasionally as a possible future application [20]. ${ }^{4}$ In general terms, images of nanotechnology that import the future into the present are used to communicate what nanotechnology is as well as to indicate nanotechnology's potential. In doing so, within science and beyond, such images are used strategically to put audiences in desired positions and at the same time to strengthen one's own position.

An interesting example is how the Foresight Nanotech Institute used the Nanogear image to position itself. On their website, they present the Nanogear image (Fig. 5) (and the image of the Strained-Shell Sleeve Bearing) to indicate that 1 day, surely, Productive Nanosystems will be realized. Robert Freitas Jr. (on the Foresight Institute's website) actually presents his images of 'respirocytes' (artificial blood cells able to carry 236 times more oxygen than human's red blood) as designs, implying that they can (and thus will) be built in the future. In other words, a design has to anticipate a future situation. What is new in nanotechnology is that these images are about aimed-for possibilities rather than an actual construction plan of such a future. The Nanogear image is an extreme example, but these kind of images and their use are widespread.

\section{Entanglements of Nanoscience and Arts}

Nanoscientists play with the entanglement of databased imaging and impressionistic imagining, and with the entanglement resulting from projecting of the future into the present. They produce and use images to illustrate scientific breakthroughs and to create expectations about the potential realization of scientific achievements, or to highlight socio-political debates. In addition, the aesthetic appeal of the images that are produced as visualizations of the nanoscale, is actively pursued, for example through

\footnotetext{
${ }^{4}$ To name one (and not very plausible) example, in a (peerreviewed) Report of the World Technology Evaluation Centre the Nanolouse was framed as a possible future application of micromanufacturing (http://www.wtec.org/).
} 
impressive colouring, as in IBM's image of the 'quantum corral' (Fig. 7). The fact that images are now given a name, and an evocative name at that, is an indication that they are seen as works of art, which have titles. ${ }^{5}$ This link with the world of art, at least with the world of being creative in making images, is not just an excursion of scientists. There is interest from the side of art as well. The forays between science and art are mutual.

An interesting development is how artists make use of, or even get involved in, the production of images through imaging instruments. As Chris Orfescu noted, there appear to be two ways to do so: nanolandscapes in which given structures of matter at the nanoscale are depicted, and nanosculptures, which are created through the manipulation of matter at the nanoscale by nanoscientists, and then visualized. ${ }^{6}$ One sees how such images offer a view to a new world that is in the process of being explored. Many of the nano- and microsculptures like the 'nano-guitar', 'nano-opera house', 'nano-toilet' and the 'nano-bull' (see Fig. 3) circulate widely and are seen as being linked to nanotech developments. The sculptures visualize what was artfully created. Interestingly, the methods which are used to create such nanosculptures are of scientific interest.

For example, Kawata et al. [8] created a model bull, measuring 10 by $7 \mu \mathrm{m}$, which is about the size of a red blood cell. The nano-bull was used to show the potential of two-photon photopolymerization. It sustains visions that microfabrication techniques - as used to create the nano-bull - could also be useful in making micromachines and drug-delivery systems [8]. But the fact that it was a bull was the immediate message, and Kawata et al.'s claim about their technoscientific achievement piggy-backed (if we may say so) on this message.

Another example comes from a nanoart project in which imaging tools like the Scanning Tunneling Microscope (STM) and Atomic Force Microscope (AFM) are deliberately used for artistic purposes. Scali and Goode produced the smallest map ever of the continent Africa, created through the use of a Scanning Electron Microscope (SEM) and visualized

\footnotetext{
${ }^{5}$ Scientists are creating impressions, as artists do. In fact, the IBM Almaden scientists sometimes describe themselves as 'artists' when they present such images.

${ }^{6}$ See http://www.nanoart21.org.
}

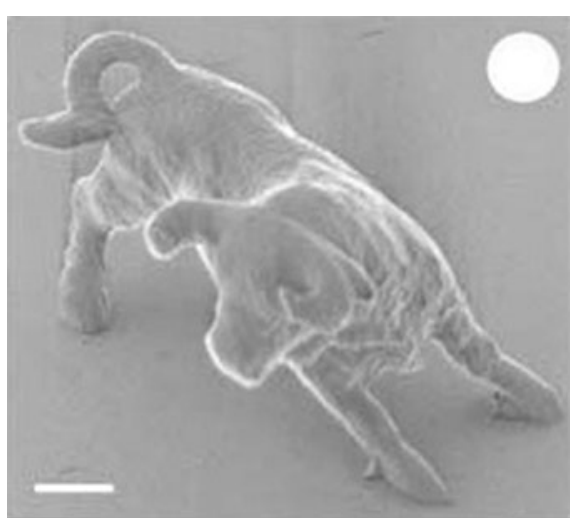

Fig. 3 Nano-bull. A team of Japanese engineers has created the smallest sculpture of a bull, which could only be viewed with a Scanning Electron Microscope. Source: Kawata et al. [8]

with an AFM (see Fig. 4). The actual size is $200 \mu \mathrm{m} \times$ $130 \mu \mathrm{m}$, and it is meant to highlight the paradox of Africa 'being geographically and anthropological central to our world, yet unrecognizable, unexplored, and invisible' ([7]: 408). Apart from the political message that requires text to be conveyed, a visualization is produced to create an aesthetic paradox: 'a piece of art that you can never see. Yet that exists and carries a message'. ${ }^{7}$ At the same time, it shows the research group's abilities to work at the nanoscale and to visualize it, and so illustrate/demonstrate the innovative character of nanotech developments.

In this way, nanoart also becomes a showcase for nanoscience. By crafting impressive nanosculptures, scientists' capacities to manipulate matter at the nanoscale are highlighted, and expectations are created about the possible applications of the new methods.

Then there are artists (often graphic artists) who create impressions of how the nanoscale could look, or give their impressions of possible future applications for nanotechnology developments. They can be commissioned to do so by scientists to enhance the visual appeal of their achievements.

The aesthetic appeal of images becomes more relevant when images are intended to circulate more widely and to reach broader audiences. This happens when imaging contests are organized where beautiful visualizations of the nanoscale are selected, and which then may become linked to more general issues and foreground nanotechnology developments

\footnotetext{
${ }^{7}$ At: http://www.nanoarte.it
} 


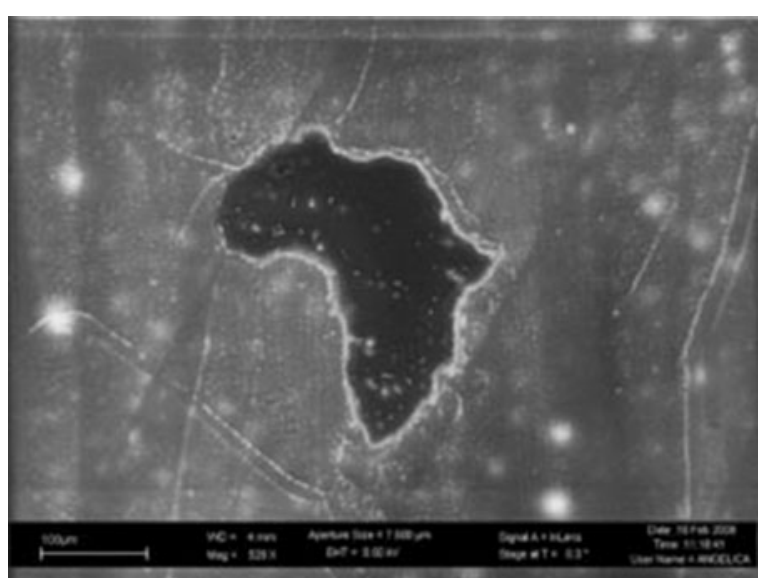

Fig. 4 Invisible continent Africa. The artwork is a small sliver of silicon, visualized with an AFM, and only visible by using the same instrument. Source: http://www.nanoarte.it

and science in general, and, importantly, the beauty of the nanoscale.

Such images might then stand for nanotechnology. The image of the Nanoflower, for example, is a nanosculpture, it was created in a laboratory, and its colouring was intentionally chosen to enhance its appeal to wider audiences. ${ }^{8}$ It was indeed used as a general illustration in texts explaining nanotechnology [20]. But it did not become an image recognized immediately as standing for nanotechnology.

\section{Images Standing for Nanotechnology}

How can images of nanotechnology become iconic, in the sense of standing for nanotechnology and its further development? There are two parts to this question about the process and what is involved. The overall process is their reception and further circulation, where the message that is conveyed also plays a role. At some moment, the image has so much standing that it can stand for nanotechnology in its own right. Secondly, there are struggles between actors with an interest in which image will eventually come to stand for nanotechnology. In a sense, whether an image becomes iconic or not is the outcome of such struggles. On the basis of these two processes, we identified three

\footnotetext{
$\overline{8}$ Toumey [22] has discussed this, and also created other colourings, to show the difference.
}

iconic images; the Nanolouse (see Fig. 2), the Nanogear (see Fig. 5) and the IBM-nanologo (see Fig. 6). ${ }^{9}$

In the case of the Nanolouse image, we have traced its circulation and reception (see [20]). After winning the Science Visions Award in 2002, the Nanolouse image circulated widely. From 2002 its occurrences increased to a peak in 2004. Its resonance with general culture helped as well. The Nanolouse image draws on, and reinforces, ideas about 'magic bullets' redressing our sorrows. While contested within science - that it might create wrong ideas about nanotechnology when presented to lay audiences (cf. [14]) - it was actually nanoscientists who continued to use the Nanolouse image in their presentations, making it available on their websites. There is a reversal in its use: first, the Nanolouse was accompanied by text explaining what the image depicted, but later, such explanations were not needed anymore; the image could speak for itself and came to stand for the future of nanomedicine.

In the case of the Nanogear image there was a general appreciation of the image in the 1990s, and a widespread uptake which made it iconic according to our definition. But with the downturn in the standing of the Drexlerian vision [18], it is not generally accepted anymore as standing for nanotechnology. The Nanogear image builds on ideas that atoms can be used to engineer products from the bottom-up, and is used as standing for molecular manufacturing, the Drexlerian vision. The image was designed by the Foresight (Nanotech) Institute to carry that message, and was used almost as a logo [20]. When the vision of molecular manufacturing lost its general standing in the early/mid 2000s, at least within the nanotechnology establishment [18], the use of the Nanogear image as standing for nanotechnology became contested. But it continued to perform outside the immediate world of nanotechnology, up to appearing in official publications and brochures of research

\footnotetext{
${ }^{9}$ For a time in the 2000, when converging technologies were pushed in the USA with particular reference to human enhancement, the image of the Vitruvian Man, used on the cover of one of the NSF Reports of the early 2000s, was widely used to indicate converging technologies - metaphorically. Its somewhat iconic status appears to have diminished, at least in the world of nanotechnology.
} 


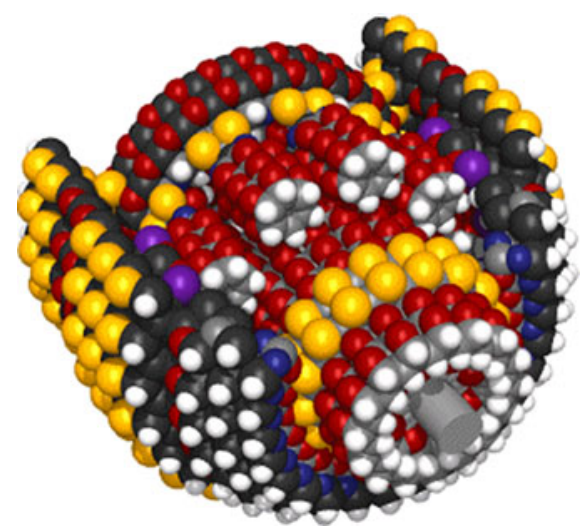

Fig. 5 The Nanogear image. The Nanogear image features a complex molecular structure which is envisioned to be used to build products from the bottom-up. This structure is designed through molecular construction software developed by Nanorex. It stands for the idea that 1 day atoms could be used as the ultimate building blocks. Source: http://nanoengineer-1.com/ content $/$ index.php?option $=$ com content \& task $=$ view\&id $=$ $52 \&$ Itemid $=62$

institutes wanting to show they were into nanotechnology as well. ${ }^{10}$

Our third iconic image, the IBM nanologo (see Fig. 6), remains uncontested. It is widely taken up and appreciated. '[It] became visually compelling evidence of the human capacity to manipulate the world "atom-by-atom" and to build various molecular devices in the future' ([21]: 54; cf. [23]). The IBM logo 'seems to suggest progression toward the "full potential" of nanotech' ([11]: 272), and stimulated imaginations of the discovery and conquest of new spaces. Mordini [13] compares the 'writing' of the IBM logo with the use of the American Stars and Stripes flag to mark territory. ${ }^{11}$ Other images produced by IBM Almaden like the elliptical corral of

\footnotetext{
${ }^{10}$ Rip and Van Amerom [18] mention a 2007 brochure of the Swiss research institute EMPA. The Foresight Nanotech Institute continues using the Nanogear image in spite of negative reactions in the mainstream nanoworld [20]. Interestingly, in the case of the term 'molecular manufacturing', they did change and now talk of Atomically Precise Productive Nanosystems. Actually, Christine Peterson, cofounder of the Foresight Nanotech Institute, emphasized in her paper, 'Thinking Longer Term about Technology' [16], the importance of relabeling to convey the same message in changing circumstances. Clearly, that was not seen as necessary for the Nanogear image.

${ }^{11}$ This a strong claim, but it is definitely the case that such images are 'rhetorical tools for making nanotechnological visions plausible to a broader public' ([21]: 54).
}

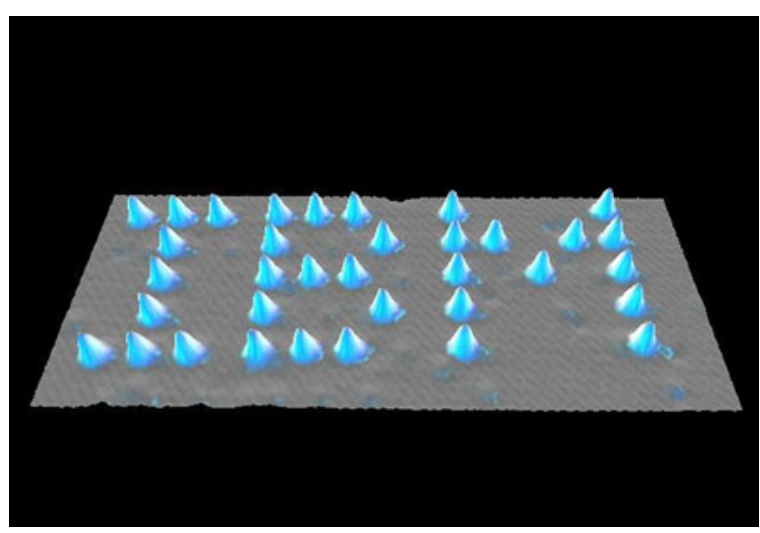

Fig. 6 IBM nano-logo. The IBM logo was created at the nanoscale by moving 35 xenon atoms on a nickel surface. This image showed that atoms could not only be visualized, but also be moved through the use of an STM. Image originally created by IBM Corporation. Cf. Eigler and Schweizer [6]

cobalt atoms on a copper substrate, with its judicious use of colours to create an aesthetically pleasing image (Fig. 7), were used as illustrations, but never became iconic.

A large variety of images of nanotechnology circulates inside as well as outside the world of nanotechnology, but most of them do not become iconic. That depends on their reception and if and how they take on a life of their own, including the struggles linked to their being "markers for territory". The three images that did become iconic all depict actual or imagined technoscientific objects, and are widely seen as representing technoscientific achievements, even when they only offer a promise.

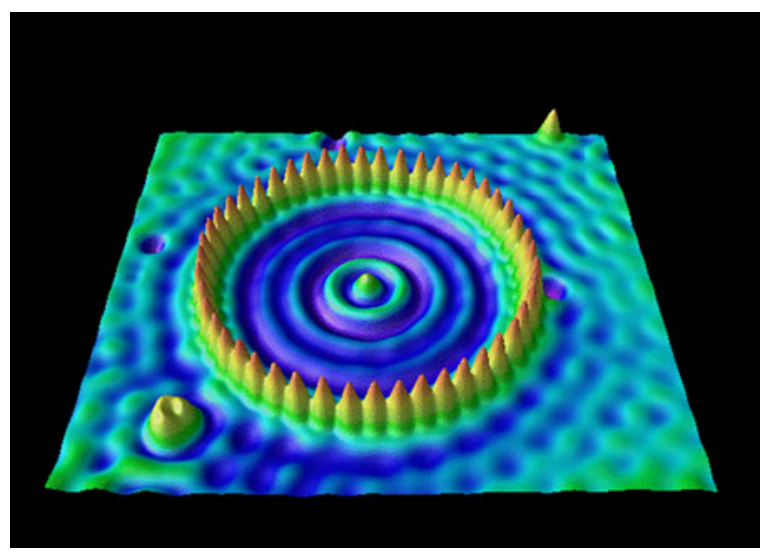

Fig. 7 Quantum Corral. Ring of atoms are shown in light shade of green, in which the ripples (colored in blue) are wave patterns of some of the electrons trapped in the corral. Source: http://www.almaden.ibm.com/vis/stm/images/stm_small.gif 


\section{In Conclusion}

The entanglement of imaging and imagining occurs all the time, and it can stabilize into specific patterns and established rules. This is very clear in practices of visualizing the nanoscale. While imaging is what these practices are about, imagining is an integral part, both in expectations about how the nanoscale could/should look like, and in the highlighting of the images, e.g. with colours, to enhance their visual appeal within the world of nanotechnology and for wider audiences. How to do this is broadly accepted, even if there are some debates. In concrete situations, there will always be choices to be made which require judgment rather than following a stabilized rule.

Incorporating the future in the present occurs in various ways, already in how images are used to visualize a design that might/should be realized. The boundary with artist's impressions of possible futures is blurred. While there are debates about the plausibility of the futures that are imagined, there is widespread acceptance of such imagining, e.g. in the use of the Nanolouse image. The cross-traffic between the world of nanotechnology and the wider world is premised on promises, and images embodying such promises are an integral part of this cross-traffic.

Thirdly, there are mutual forays between art and nanoscience/nanotechnology. While there is interest from both sides, there is little stabilization (and perhaps there shouldn't be). Seen from the world of nanotechnology, art is peripheral, so there is no pressure to stabilize the entanglements. This is different from the situation of visualization of the nanoscale, where the entanglement of imaging and imagining is addressed daily, and stabilization is necessary to work productively. For the entanglement of the present and the future, there is some pressure to stabilize, but also opportunism: if images like the Nanolouse appear to work, they are used even if they could be (and had been) criticized.

There are tensions in the entanglements and their stabilization. Already within scientific practices, struggles become clearly visible when images are used to reach out to broader audiences. Because the future and the present are entangled in nanotechnology and its images, there are always possibilities to emphasize one side over the other, in terms of simple actor's categories of 'reality' vs. 'fiction' or in more subtle ways. The example of the Nanolouse image shows that its fictional character is often downplayed in order to profit from the associations (like "magic bullet) elicited by the image. This went as far as the image being featured in the documents of the European Technology Platform Nanomedicine. At some moment, there may be a backlash, however, when actors in the world of nanomedicine get frustrated by the expectations that were induced by the wide use of the Nanolouse image.

For nano and art, there may be tensions between nano-actors thinking in terms of aesthetics, while artists focus on 'creating a new reality'. ${ }^{12}$ There are no antagonisms, because the worlds of artists and of nanoscientists are far apart, and the interactions are seen merely as intriguing curiosities. There is a gray area where graphic designers produce images, and nanoscientists like Chris Ewels dabble in graphic design. At the moment, there is space for all of these ventures. The umbrella term 'nanotechnology' covers many images, and from different sources. There is little competition, and thus little struggle.

This will change when images (of whatever provenance) might come to stand for nanotechnology as a whole. ${ }^{13}$ Then there is something at stake: nanotechnology is not something given - it lives on promises. So, the struggle will not be about what nanotechnology is now (even if that is one element), but about what nanotechnology could be and should be. These struggles occur in a variety of arenas, like funding programs, national science and technology priority setting, and eligibility of who is allowed to speak for nanotechnology. Images play a role as resources in these struggles, but also as agents in their own right when they have a life of their own. Not as an active force, but as an affordance or a repertoire which will shape what happens without being determinant. It is the entangled imag(in)ing which creates such affordances and repertoires, not the force of images as such.

\footnotetext{
${ }^{12}$ We are grateful to Chris Robinson who during the workshop in Bergen, 27-29 January 2011, drew our attention to this way of characterizing art, including a reference to Burnham [4].

${ }^{13}$ While there is no such 'whole' of nanotechnology, this is how it features in discourses.
} 
Acknowledgements We thank Fern Wickson, Rasmus Slaattelid, Chris Robinson and Vincent Bontem, and other participants in the Bergen Workshop (27-29 January 2011) for their useful comments. The research on which this paper is based was funded through the Dutch R\&D consortium NanoNed.

Open Access This article is distributed under the terms of the Creative Commons Attribution Noncommercial License which permits any noncommercial use, distribution, and reproduction in any medium, provided the original author(s) and source are credited.

\section{References}

1. Andre G, Kulakauskas S, Chapot-Chartier M-P, Navet B, Deghorain M, Bernard E, Hols P, Dufrêne YF (2010) Imaging the nanoscale organization of peptidoglycan in living Lactococcus lactis cells. Nat Commun 1:27. doi:10.1038/ncomms 1027

2. Bachtold A, Hadley P, Nakanishi T, Dekker C (2001) Logic circuits with carbon nanotube transistors. Science 294:13171320

3. Brown MB (2009) Science in democracy. Expertise, institutions and representation. MIT Press, Cambridge

4. Burnham J (1971) The structure of art. George Braziller, New York

5. Collins HM (1992) Changing order: replication and induction in scientific practice. University of Chicago Press, Chicago

6. Eigler DM, Schweizer EK (1990) Positioning single atoms with a scanning tunneling microscope. Nature 344:524-526

7. Feresin E (2007) The Invisible Continent. Nature 449:408

8. Kawata S, Sun HB, Tanaka T, Takada K (2001) Finer features for functional microdevices: micromachines can be created with higher resolution using two-photon absorption. Nature 412:697-698

9. Kaiser M (2006) Drawing the boundaries of nanoscience rationalizing the concerns? The Journal of Law, Medicine and Ethics 34(4):667-674

10. Lenhard J (2004) Nanoscience and the Janus-faced character of simulations. In: Baird D, Nordmann A, Schummer J (eds) Discovering the nanoscale (pp 93-100). IOS Press, Amsterdam

11. Milburn C (2002) Nanotechnology in the age of posthuman engineering: science fiction as science. Configurations 10 (2):261-295
12. Mody CCM (2004) Small, but determined: technological determinism in nanoscience. Hyle 10:99-128

13. Mordini E (2007) The narrative dimension of nanotechnology. Nanotechnology Perceptions 3:15-24

14. Ottino JM (2003) Is a picture worth 1,000 words? Exciting new illustration technologies should be used with care. Nature 421:474-476

15. Persson M (2003) Fraaie platen in saaie bladen. De Volkskrant, December 20

16. Peterson C (2008) Thinking longer term about technology. In: Fisher E, Selin C, Wetmore JM (eds) The yearbook of nanotechnology in society. Volume 1: Presenting Futures. Springer, Dordrecht, pp 37-47

17. Preston AM, Wright C, Young JJ (1996) Imag(in)ing annual reports. Account Organ Soc 21(1):113-137

18. Rip A, Van Amerom M (2010) Emerging de facto Agendas around nanotechnology: two cases full of contingencies, lock-outs, and lock-ins. In: Kaiser M, Kurath M, Maasen S, Rehmann-Sutter C (eds) Governing future technologies. Nanotechnology and the rise of an assessment regime. Springer, Dordrecht, pp 131-155

19. Ruivenkamp M, Rip A (2010) Visualizing the invisible nanoscale: study of visualization practices in nanotechnology community of practice. Sci Stud 23(1):3-36

20. Ruivenkamp M (2011) Circulating Images of Nanotechnology. Dissertation, University of Twente

21. Schummer J (2006) Gestalt switch in molecular image perception: the aesthetic origin of molecular nanotechnology in supramolecular chemistry. Found Chem 8:53-72

22. Toumey C (2007) Cubism at the nanoscale. Nat Nanotechnol 2:587-589

23. Toumey C (2010) 35 atoms that changed the nanoworld. Nat Nanotechnol 5:239-241

24. van Lente H (1993) Promising technology - the dynamics of expectations in technological developments. Dissertation, University of Twente

\section{Websites}

25. http://www.almaden.ibm.com/vis/stm/images/stm_small.gif

26. http://www.bbc.co.uk

27. http://www.nanoart21.org

28. http://www.nanoarte.it

29. http://nanoengineer-1.com/content/index.php?option= com_content\&task $=$ view\&id $=52 \&$ Itemid $=62$

30. http://www.wtec.org 